\title{
Development of land use and transport dynamics model for the impact evaluation of urban development policy
}

\author{
Nunu Noviandi ${ }^{1}$ * , Iwan P. Kusumantoro ${ }^{2}$, Muhammad Tasrif ${ }^{2}$, Pradono Pradono ${ }^{2}$ \\ ${ }^{1}$ Center of Technology Assessment for Specific Zone, Agency of Technology Assessment and Application (BPPT), Jakarta, \\ Indonesia \\ ${ }^{2}$ School of Architecture, Planning, and Policy Development, Institut Teknologi Bandung (ITB), Bandung, Indonesia
}

\section{A R T I C LE IN F O}

\section{Article history:}

Received 10 August 2016

Received in revised form

20 September 2016

Accepted 5 October 2016

Keywords:

Urban systems

System dynamics

Spatial dynamics

Outcome trade off

Policy resistant

\begin{abstract}
A B S T R A C T
The Dynamic model of the interaction between land use and transport in urban areas is developed in order to meet the needs of city managers in formulating the more comprehensive urban development plans. The specialty of the model lies in the method that was built through the integration between the methods of system dynamics with spatial dynamic. The utilization of this method is intended to address the challenges in developing a model that is able to describe the dynamics of relationship between land use and transportation in the perspective of urban system. Application of this model in the research area shows some unique phenomenon in the study area such as a tradeoff policy outcome and system resistance to the policy.
\end{abstract}

(C) 2016 The Authors. Published by IASE. This is an open access article under the CC BY-NC-ND license (http://creativecommons.org/licenses/by-nc-nd/4.0/).

\section{Introduction}

become more open. As the result, external factors influencing the intensity of development will also increase. Autonomy era which coincided with globalization era will put cities in a very tight competition mechanism. In the future, the existence of a city will be determined by the city manager's ability to manage the factors that influence the development of the city, efficiently and effectively (Alkadri, 2002).

Efforts to increase the speed of city managers in understanding the changes, analyzing and adjusting development policies in the region, cannot be separated from efforts to enhance the role and function of technology in the planning and implementing policies (Niosi et al., 2010). One of The obstacles faced by the city manager to keep in line with developments in the region are the limitation of technology which is able to provide the ease of understanding the city as a dynamic system and also inability of the manager to master all the problems.

An analysis on planning techniques and policy formulation for cities in Indonesia showed that most of techniques that have been utilized all this time tend to use the static models. As a result, these models are less adaptive to changes that occur in the internal and external elements of a city system (Noviandi and Pradono, 2013). This paper presents the results of research that develop models of land use and transport linkage using the framework of the dynamic urban system. The development of a dynamic based model is an effort to fill the shortage of land use and transportation models that 
accommodate the formulation of policy scenarios, based on the principles in urban development which are complex, dynamic and systemic.

\section{Concept and method}

\subsection{Literature review}

The interaction models between land use and transport in urban areas are generally built to model the phenomenon of land use and transport in a large scale. Because of the scale, the models are less able to help in the formulation of policy alternatives in order to anticipate the dynamic trend of urban growth (Wee, 2015).

The understanding of the interaction of land use and transport in urban areas can no longer be done partially. The interaction of land use and transport should be viewed comprehensively as a whole system with other urban components such as economic, social and environmental (Kulmer et al., 2014). The failure of the city government to provide policies that anticipate the dynamics problems of land use and transport is often preceded by the limitations in understanding the phenomenon systematically (Sanders, 1996).

Some methods have been quite a lot developed in order to assist the city managers in formulating policies. Some of the findings as a result of the review for related models that usually used as tools for urban development policy formulation are:

- Components of urban system that used in the model are limited, so these model less representing the actual elements of urban system (Sanders, 1996).

- The level of model complexity has not shown by the many linkages between urban elements, but rather by the complexity of mathematical calculation (Boumans, 2012).

- The pattern of linkages between components is adopted but only limited for the correlation pattern, not for the causal relationship (Pfaffenbichler, 2003)

- The methodologies used in the model were intended to seek equilibrium, maximum entropy and maximum utility obtained by the iterative process (Sterman, 2000), so it does not reflect the urban phenomenon of "dynamic complexity".

- Simulations of policy scenarios are difficult to be done due to the growth of demand for land, and the movement comes from exogenous information (Pfaffenbichler, 2003).

- Group disaggregate models are models that try to detail the components that exist in the previous generation model. The method used primarily is multinomial logit method with the principle of maximum utility (Patterson et al., 2010).

- Group activity based models have differences in its conception. In this model there are two important components, which are agent and the preferences of the agent to the location or preferences to the choice of transport mode.
- Meanwhile the models in the era of 2008-2013 more represented the development of approach methods that used in the previous generation model. Emphasis on understanding about the behavior of individuals to participate in land-use change, the selection of the location of residence and work location as well as the decision to participate actively in the movement became concern of models in this generation (Acheampong and Silva, 2015).

The challenges, on-going progress and future research directions of the land use and transport interaction model will be around the following thematic areas: 1) the challenges imposed by disaggregation-data availability, computation time, stochastic variation and output uncertainty; 2) the challenges of progress in integrating activity-based travel demand models into LUTI models; 3) the quest for a satisfactory measure of accessibility; and 4) progress and challenges toward integrating the environment into LUTI models (Acheampong and Silva, 2015).

\section{Concept of the model}

Most experts argue that the direction of the land use and transportation model development in the future will be on the specific model, contextualdomain-activity based, disaggregate, and also microsimulation (Felsenstein et al., 2010). Referring to that opinion, the concepts of model which will be developed through this research are as follows:

- This model will adopt not only the needs for microscopic behavior of the urban system but also to accommodate the dynamics of behavior of urban system at macroscopic level. It is based on the basic concept used in the model in the context of complex urban dynamics; each urban component is linked to one another either horizontally or vertically.

- This model will accommodate the needs of adaptive model, based on spatial behavior (Iacono et al., 2008), transparent and facilitate policy synergies, and also can model the structure of the city as a dynamic and complex phenomenon (Pfaffenbichler, 2003).

- This Model is developed according to the research goal which is to help better understanding about the dynamics of interaction between land use and transport system within the framework of the dynamics of urban systems, so that the level of modeling was developed hierarchically from the macro level to the micro level.

In this research, the phenomenon is modeled hierarchically from urban scale to the scale of the network cell as in Fig. 1.

Model at city-scale will focus on linkages of five (5) city sub-systems covering urban land use, transportation, economic, social, and environment. The main output of the model at city level is the performance of demand land requirements, and demand needs of transportation. Development of a 
model in an urban scale is intended to illustrate how policies can affect the dynamics of land use and transportation in non-linear.

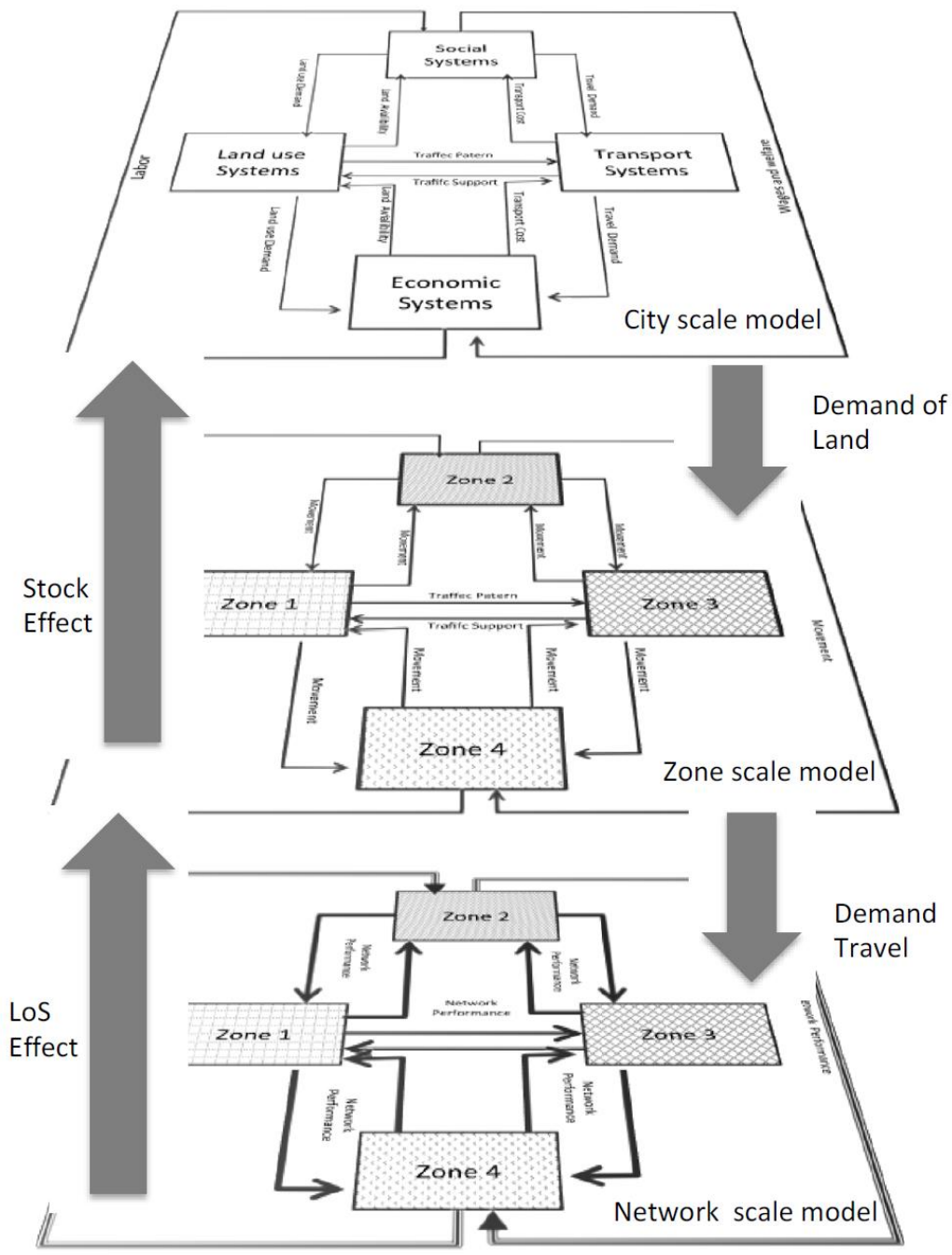

Fig. 1: Concept of the model
City Scale Model :

- Urban system Sttructure

- Policy Framework

- City Component Behavior

- Development Demand

- Regional/external Effect
Zone Scale Model :

- Land use change and conversion

- Zone regulation

- Demand Distribution

- Trip Generation

- Travel Distribution

- Spatial movement pattern
Link Scale Model :

- Network performance

- Road capacity

- Network Level of service

- Transport suplly

- Transport level of service
Meanwhile at zone scale, the model will be focused on modeling the changes of land use in each zone, population dynamics and movement between the zones. Model at zone scale intended to illustrate the dynamics of the complexity of the relationship of land use and transportation which is influenced by factors that came from internal zone or factors that derived from the model at city level.

The link model of cell/grid will be focused on the analysis/modeling of spatial movement patterns of land use and its impact on spatial dynamics and also on population movement from each zone in the road network platform. Model on a scale cell / road network is intended to describe the performance level of transportation services due to changes in land use and government policy concerning provision of transport facilities and infrastructures.

\section{Methodology}

Based on the concept of the model developed, the methods needed for the development of this model should at least meet the following specifications:

- The methods used must be able to translate the reality of the relationship between the components of land use with transportation and other components in the urban system, both qualitatively and quantitatively. These linkages in accordance with the nature of the urban have a non-linear properties, has a causal connection, and taking into account the delay. Methods must have the ability to portray the explicit feedback.

- The method used should be in line with the real behavior of urban systems that tend to be disequilibrium, so the paradigm approach to the system used is a group of "servomechanism". The method is expected to assist in modeling the urban structure behavior that is "dynamic complexity"(Richardson, 1991).

- The methods used must be able to support the integration process scale model of the macro-meso and micro. One important aspect is the ability of the model to overcome the difference in behavior between the time dimension of the system behavior on a macro level, meso and micro

- The method developed at least must be able to accommodate the uncertainty so that the model must be adaptable to the changes in the urban system component. 
- The methods used, according to the challenge of model development, were able to avoid the "black box dilemma". The method should support the transparency in endogenous models

- The method developed should be able to describe the behavior of the dynamics interaction of land use with transportation spatially. Changes in land use will affect transport and vice versa must be illustrated spatially and dynamically.

To meet the requirements of the methodology, the alternative method that can be used is the integration between system dynamics and spatial dynamics method. The use of system dynamics method is intended to emphasis purpose of modeling the structure of urban system phenomenon that determines the behavior of the system as a whole. Meanwhile spatial dynamics method is the method that can be used to understand and model the spatial behavior of urban system phenomenon, where the interaction between land use and transportation became the main issue (Fig. 2).

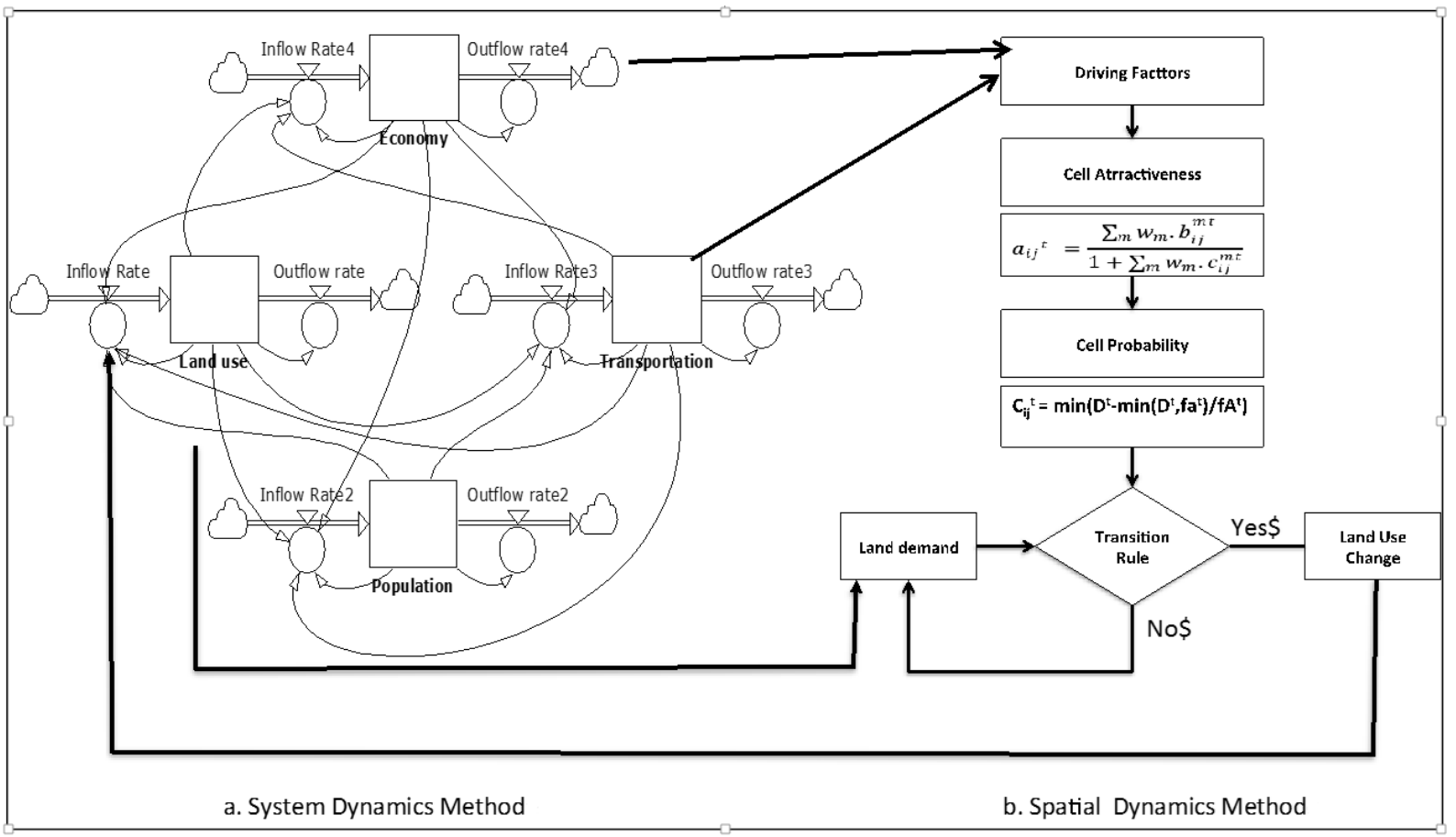

Fig. 2: Component of model method

\section{Applied model for policy evaluation}

\subsection{Policy scenario}

The testing of the model was carried out by applying the model in the evaluation process of spatial planning policy in the city of Bekasi Indonesia. Bekasi city spatial planning has been established as a county regulation in 2011 . Thus any form of physical development should refer to the content of the plan.

In the development of the city until today, the dynamics of economic development and rapid population resulted in a lot of development that is not in accordance with the spatial plan especially housing construction. For that reason the evaluation process needs to be done.

In applying the model, scenarios are developed by combining urban development policies and then the result of each scenario will be evaluated. The combination of policies is covering spatial planning policy, economic policy, transport policy and population policy. Spatial planning policies related to the allocation and distribution patterns of cultivation and conservation area, economic policy related to government spending and investment, transport policy with regard to the development of road networks and public transport, while the population policies related to birth control and in-migration.

The policies scripted run simultaneously so that the impact on urban development, especially the development of land use and transport can be described in the short, medium and long term. The scope of the policy scenarios and parameters used can be seen in Fig. 3 and Table 1.

\section{Simulation result}

The predictions of Bekasi City behavior as the result of policy scenario simulations using the researched models are:

- Bekasi city's economic growth is predicted to a slightly decline from an average rate of $6.2 \%$ peryear in 2016, become $6.1 \%$ per year in 2030. The growth of main economic sectors of the city such as industrial, commercial and services sector are also experiencing the same growth pattern (Fig. 4).

- Bekasi urban population growth rate is estimated to be relatively unchanged at $11.3 \%$ per year. The population growth rate is resulted in from large additional of population every year, primarily due to in-migration. In migration in Bekasi city 
achieved an average growth of $11.1 \%$ per year (Fig. 5).

- Land settlement is estimated to grow by an average of 105 hectares per year, industrial land will increase by an average of 32 hectares per year, land for commercial and services will increase by an average of 402 hectares per year, while agricultural land and open space will decrease at average 994 hectares per year (Fig. 6).

- Service performance of transport system in Bekasi City is predicted to decline significantly. LOS (Level of Services) is predicted to continuously decline towards classification E (Fig. 7).

Table 1: Policy parameters for impact evaluation

\begin{tabular}{|c|c|}
\hline Policy Type & Parameters \\
\hline Spatial & Land use allocation as city spatial plan \\
\hline Economic & Investment growth 10\% per year*; government expenditure growth 15\% per year* \\
\hline Social & Family Planning Program in 2005-2030; no restricted policy for in migration \\
\hline Transport & Development road as city structure plan; public transport services 20\% total travel \\
\hline
\end{tabular}

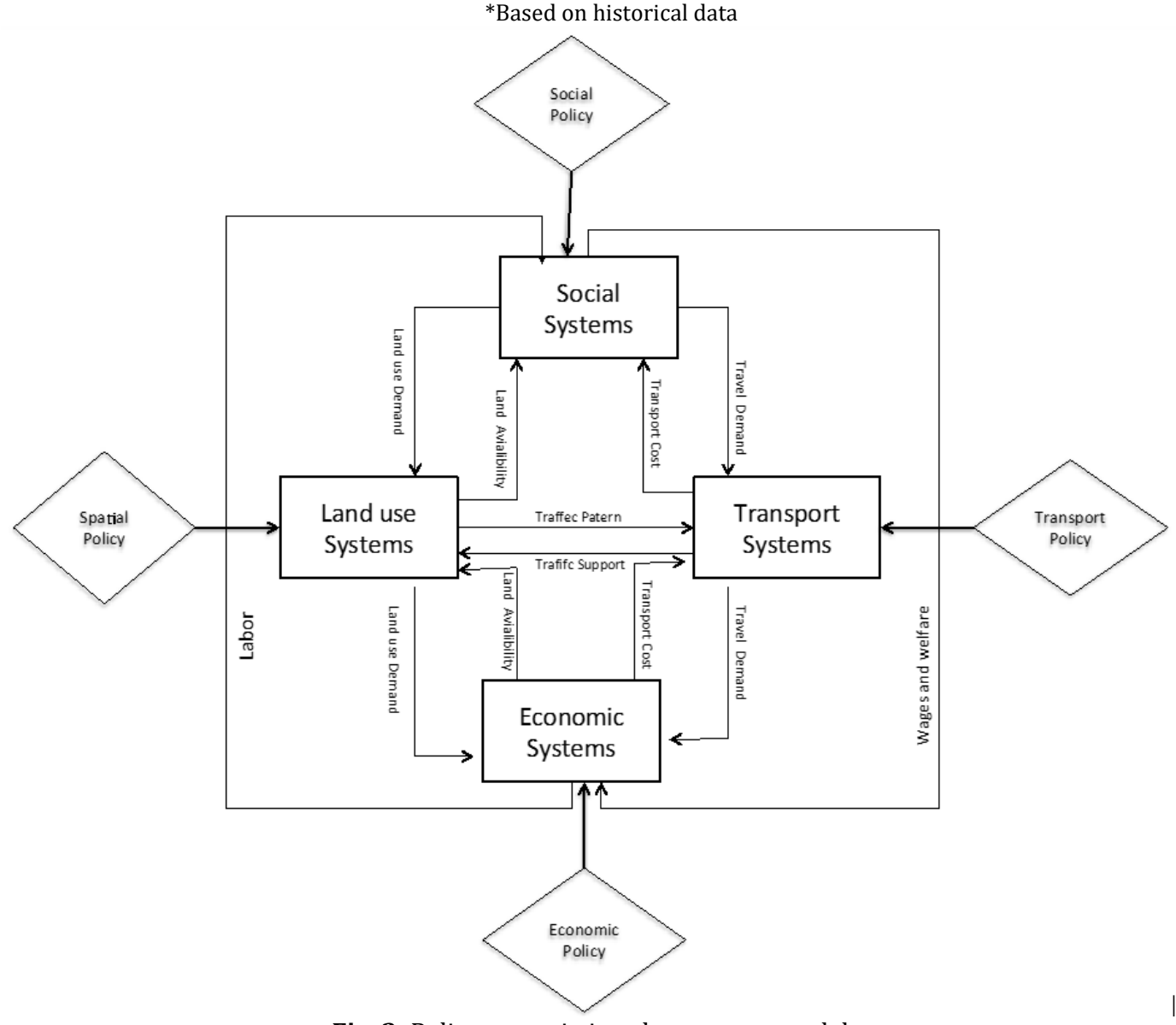

Fig. 3: Policy scenario in urban system model



Fig. 4: Prediction of economic growth of Bekasi city 


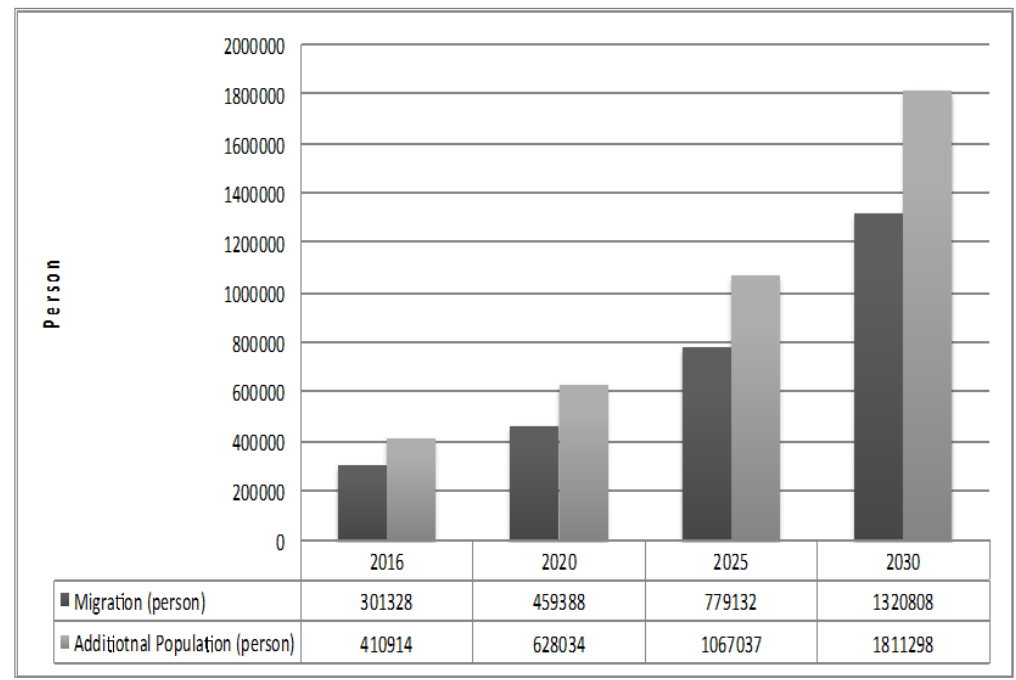

Fig. 5: Prediction of population growth of Bekasi city

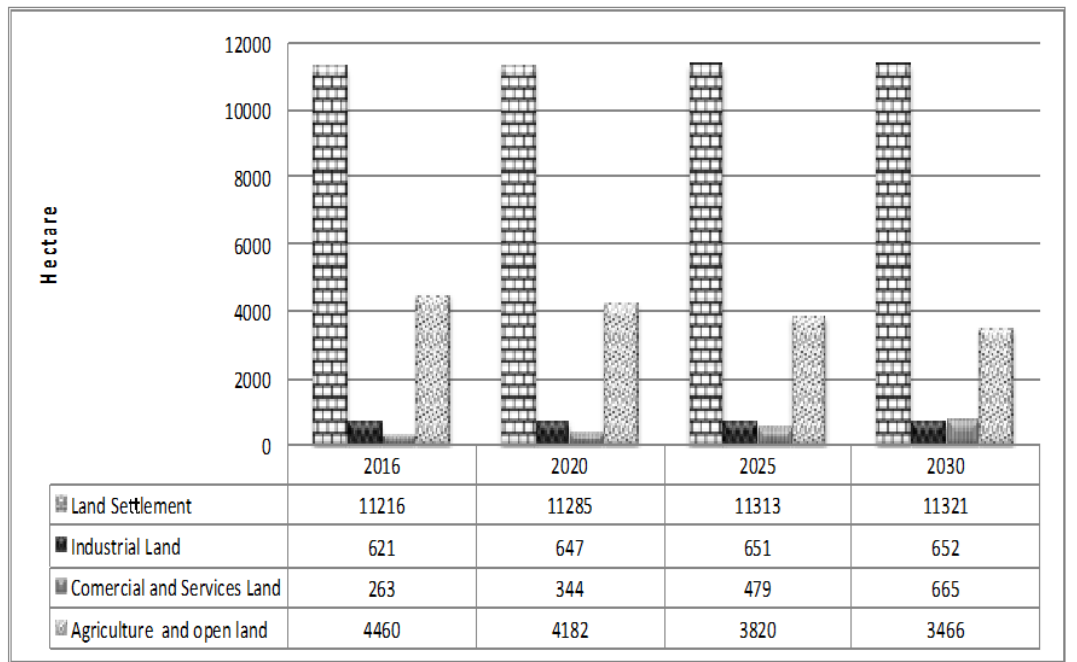

Fig. 6: Prediction of land use growth of Bekasi city
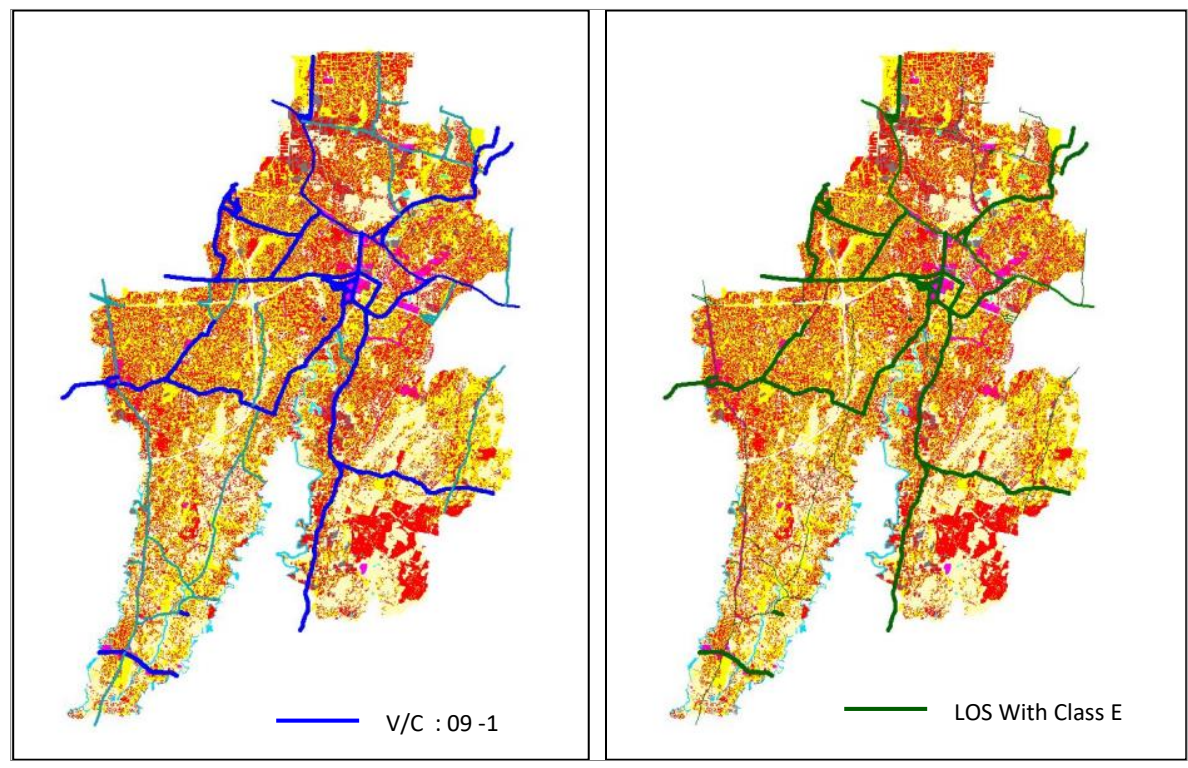

Fig. 7: Prediction of transport level of services in 2030

\section{Findings}

Some important findings on the evaluation of urban development policy by using the researched models are:
- Scenarios of policy that was imposed on the model, predicted a relatively stagnant and declining economic growth of the city. It can be identified that, the economic and transport policies not 
significantly affected the performance of the city's economic growth.

- Spatial policies, which allocate the space for economic activities such as: industrial, commercial and services based on city spatial plan will affect significantly on the economic growth pattern. Furthermore, the economic growth pattern tends to be stagnant and decline caused by the effects of the ratio between the level of land utilization for economic activities with land allocation based on the spatial plan has approached 1 (one).

- The increasing on land utilization for commercial and services can be identified in a very high rate of changes. This condition occurs because of land conversion from residential to commercial activities and services. In general, land conversion is a process that is contrary to the city spatial plan.
- The pattern of economic growth can be identified to be relatively stagnant but will still produce high in migration flows to Bekasi City. Furthermore this condition will cause high population growth in Bekasi City. The absence of policy restrictions on migration, and the lack of effective family planning programs have resulted in a high growth rate of population in Bekasi City which averaged 11\% per year. High population growth has resulted high demand for residential land. The average demand for residential land in Bekasi city is estimated at 105 hectares per year.

- High demand for residential land caused the conversion of agricultural land and open space. Part of the land conversion process is contrary to the spatial plan of Bekasi City. The incompatibility of residential land development does not only occur on land allocation, but also on the direction and pattern of distribution (Fig. 8).

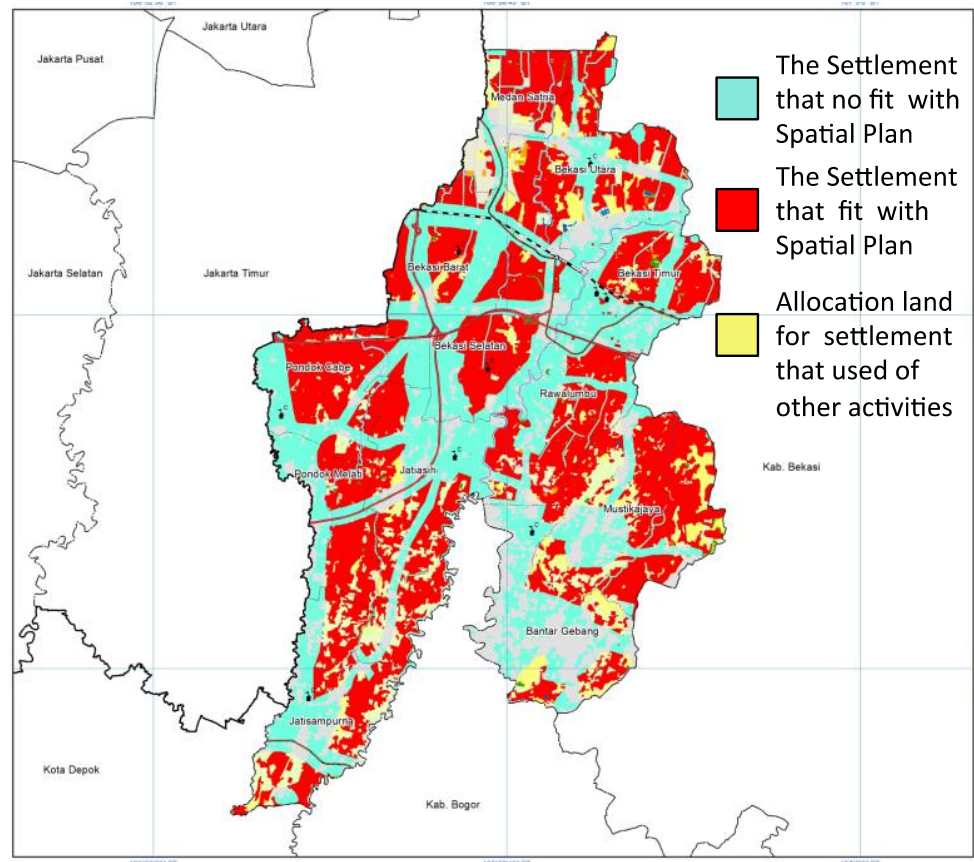

Fig. 8: Deviation of land settlement

-High growth of residential area caused the failure on transportation capacity due to the increasing demand of movement. The performance of transportation services with existing policies will not be able to meet the minimum service standards of transportation services in the city for the next 510 years.

\section{Conclusion}

The implementation of land use and transportation models in evaluating development policies of Bekasi city shows that the model-based system can help the city planners to better understand the complexity of the problem. The model can describe how trade off occurs between one policy with other policies. The model also can indicate the behaviors of urban components such as land use and transportation are likely to be resistant or insensitive to a policy.

The result of the application of the model strengthens the argument that in developing the models that integrate land use and transport in urban areas needs the perspective of macro-meso and micro. Abandonment of links of those perspectives will lead to incomplete understanding of the dynamics problems of land use and transportation in urban areas.

The most important thing in modeling the city as a system is how to understand the pattern of reciprocal relationships that occur between system components. The simulation results showed that land use policy will affect the pattern of movement and the level of service of the city's transport system. Instead, the city's transportation system also determines the direction and pattern of development of land use in the study area. 
In the context of urban development policy evaluation, the model provides an overview of how the land allocation for residential, industrial, commercial and services should be provided. The model also provides an overview of certain areas which need the development of new network road in order to change the direction of settlement patterns so that the development of the city can be equally distributed.

\section{Acknowledgment}

We thank for Ministry of Research and Technology that have sponsored this research, and government of Bekasi city that have helped to provide data and information, and Agency of Geospatial Information for the geospatial data provision. We are grateful to Institute Technology of Bandung for supporting this research activity.

\section{References}

Acheampong RA and Silva E (2015). Land usetransport interaction modeling: A review of the literature and future research directions. Journal of Transport and Land Use, 8(3): 1-10.

Alkadri (2002). Management technology for regional development. BPPT Press, Jakarta, Indonesia.

Boumans RM (2012). Integrated transportation and land use models: systems approaches and applications for modeling transport alternatives. TRC Report No. 12-001, University of Vermont Transportation Research Center.

Felsenstein D, Axhausen K and Waddell P (2010). Land use-transportation modeling with UrbanSim: Experiences and progress. Journal of Transport and Land Use, 3(2): 1-3

Iacono M, Levinson D and El-Geneidy A (2008). Models of transportation and land use change: a guide to the territory. Journal of Planning Literature, 22(4): 323-340.
Kulmer V, Koland O, Steininger KW, Fürst B and Käfer A (2014). The interaction of spatial planning and transport policy: A regional perspective on sprawl. Journal of Transport and Land Use, 7(1): 57-77.

Niosi J, Ramos JD, Fiksel J, Pérez Luna F, Kaminsky, M, Franco SD and Segara G (2010). Building national and regional innovation systems: institutions for economic development (No. E14297). Edward Elgar Publishing Limited, Massachusetts, USA.

Noviandi N and Pradono TM (2013). Readiness of urban land use and transportation planning technique to anticipate increasing complexity of the urban dynamics. Proceeding of $2^{\text {nd }}$ Planocosmo International Conference, Bandung, Indonesia

Patterson Z, Kryvobokov M, Marchal F and Bierlaire M (2010). Disaggregate models with aggregate data: Two UrbanSim applications. Journal of Transport and Land Use, 3(2): 5-37.

Pfaffenbichler P (2003). The strategic, dynamic and integrated urban land use and transport model MARS (Metropolitan Activity Relocation Simulator). Unpublished PhD Thesis, Technische Universitaet Wien. http://www. ivv. tuwien. ac. at/publications/online/MARS smallest size. pdf.

Richardson GP (1991). Feedback thought in social science and systems theory. University of Pennsylvania Press, Philadelphia.

Sanders L (1996). Dynamic modelling of urban systems. Spatial analytical perspectives on GIS. Taylor and Francis, London.

Sterman JD (2000). Business dynamics: systems thinking and modeling for a complex world. Irwin McGraw-Hill, Boston, USA.

Wee VB (2015). Viewpoint: Toward a new generation of land use transport interaction models. Journal of Transport and Land Use, 8(3): 1-10. 